\title{
BIOMASS ALLOCATION AND TRADEOFFS OF PEDICULARIS LONGIFLORA RUDOLPH. AT TWO SLOPE ASPECTS IN AN ALPINE MEADOW OF THE EASTERN TIBETAN PLATEAU
}

\author{
WANG, J. ${ }^{1,2, \#}-$ GAO, J. ${ }^{1,3, \#}-\mathrm{WU}, \mathrm{Y}^{1}{ }^{1}-\mathrm{SUN}, \mathrm{J}^{4}-\mathrm{XU}, \mathrm{B} .^{1,3}-\mathrm{SHI}, \mathrm{F} .{ }^{1}-\mathrm{BISHT} \mathrm{N}^{2}{ }^{2}-\mathrm{XU}, \mathrm{J} .{ }^{5}$ \\ $-\mathrm{WU}, \mathrm{N}^{1,2^{*}}$
}

${ }^{1}$ CAS Key Laboratory of Mountain Ecological Restoration and Bioresource Utilization and Ecological Restoration and Biodiversity Conservation Key Laboratory of Sichuan Province, Chengdu Institute of Biology, Chinese Academy of Sciences, Chengdu 610041, China

${ }^{2}$ International Centre for Integrated Mountain Development (ICIMOD) G.P.O. Box 3226, Kathmandu, Nepal

${ }^{3}$ University of Chinese Academy Sciences, Beijing 100049, China

${ }^{4}$ Institute of Geographical Sciences and Natural Resources Research, Chinese Academy of Sciences

${ }^{5}$ Haikou Institute of Land Surveying and Mapping, Haikou 570125, China

${ }^{\#}$ These authors contributed equally to this study.

*Corresponding author

e-mail:wuning@cib.ac.cn

(tel: 0086-13-980589010; fax: +0086-28-82890288)

(Received $21^{\text {st }}$ Jun 2016; accepted $11^{\text {th }}$ Jan 2017)

\begin{abstract}
Pedicularis longiflora is a typical grassland plant located in the alpine habitat in wet meadows or besides streams. This paper addresses the response and adaptation of $P$. longiflora under heterogeneous environmental conditions at different slope aspects in an alpine wet meadow, eastern Tibetan Plateau. The results show that $P$. longiflora at the southeast slope benefited more for its development and population maintenance. It also showed a relatively greater leaf biomass. However, $P$. longiflora invested more biomass to reproductive organs at the southwest slope aspect, where this species has better population continuation. Isometric scaling existed in coupled organ biomasses of $P$. longiflora which indicated that genetic regulation plays a key role in biomass allocation. $P$. longiflora allocated more biomass to aboveground parts, vegetative biomass, and non-photosynthetic organs biomass according to tradeoff values, respectively. In addition, both biotic and abiotic factors influenced biomass production of $P$. longiflora. Thus, soil temperature and interspecies competition in different habitats needs to be clearly understood and paid more attention to for cultivation and better industrialization of this herbal medicinal plant.
\end{abstract}

Keywords: biomass partitioning; allometric scaling; herbal medicinal plant; mountain resource; slope exposure; heterogeneous habitats

\section{Introduction}

Biomass partitioning is one of the most successful theories in modern ecology (Stearns, 1992), which drives water and nutrient absorption as well as carbon assimilation for potential utilization by plants (Poorter et al., 2012). Moreover, biomass allocation pattern plays an essential role in the life history of plants (Reekie and Bazzaz, 2005), because biomass is not only associated with morphological, growth and reproductive 
traits (Allaie et al., 2006), but also associated with metabolism, $\mathrm{CO}_{2}$ assimilation, and carbon sequestration. Plant height plays a crucial role of ecological variation in the species for survival, competitive ability and reproduction (Cornelissen et al., 2003), and it is related to many important functional traits (Westoby 1998; Westoby et al., 2002; Poorter et al., 2003). Little is known about height growth patterns and associated mechanisms in herbaceous species (Sun and Frelich, 2011). A study of plant height and biomass allocation at different habitats under a global climate change background can give us information on the properties and plasticity of the plant species for ecological adaptive strategy.

There has been continuous debate over the isometric or allometric allocation in different studies by several authors (McConnaughay and Coleman, 1999; Enquist et al., 1998; Enquist and Niklas, 2002; Shipley and Meziane, 2002). It is fundamental to illustrate whether allometric growth is common nature or not, which aims to figure out scaling correlations between part and whole, and part and part of one species, or one genre of plant by their deviation and comparison (Niklas and Enquist, 2001; Niklas, 2005;). Assuming that most partitioning issues are triggered by allometric growth, allometric growth can also be conducted to quantify the relationships between growth and partitioning (Weiner, 2004). Among the different plant organs, leaf plays a crucial role for dry matter production by photosynthesis, whose growth regulation has direct effect on photosynthesis efficiency of plants; while the flower is a crucial reproduction organ, whose growth regulation is inherently associated with the continuation of populations. Thus, the study of allometric growth aims to elucidate the variation of biomass allocation patterns at different habitats, and to further show the plants ecological adaptive strategy to different habitats.

Allocation of above ground biomass (AGB) and below ground biomass (BGB) has been extensively discussed for root to shoot $(\mathrm{R} / \mathrm{S})$ ratio, which plays an important role in carbon cycle models (Allaie et al., 2006; Enquist and Niklas, 2002; Wu et al., 2013). For certain species, given that the plant biomass allocation is largely genetically regulated, environmental factors can still flexibly shift investments towards the needed structures, whose allocation patterns of plastic resource are also in response to varying growing conditions (Allaie et al., 2006; Patty et al., 2010). Thus, there exists a potential practical value to quantify the trade-off relationships of multi-objects with computational formula (Bradford and D'Amato, 2012). Root-shoot interaction is species-specific in alpine grasslands, and plants have trade-offs of morphological shifts between roots and shoots to adapt to stressful environment (Song et al., 2006), to increase water or nutrient absorption for survival in the harsh environment. Furthermore, trade-offs also occur between vegetative biomass and reproductive biomass, as well as non-photosynthetic organs biomass and leaf biomass.

Pedicularis longiflora Rudolph. is a species of the Scrophulariaceae, Pedicularis Linn. It is widely distributed in the alpine wet meadows, and is a typical hygrophilous plant across 2700-5300 $\mathrm{m}$ a.s.l. in the Tibetan Plateau. It is used in traditional Chinese herbal medicine with broad spectrum effects, as an antivirus and for anti-inflammation, and treatment done from the nucleoside chemical compound found in the plant. There have been reports about the extraction of inosine and adenosine from $P$. longiflora with medicinal value (Wang and Jia, 1996; Chu et al., 2009) and not much about their preferred habitats and biomass production correlations with environmental factors. A few studies on its habitat degradation have been done but not from an ecological aspect, in particular, taking biomass production into account for practical utilization (Zhao et al., 2009). Therefore, this study was carried out to address the biomass production and allocation in Pedicularis longiflora as well as its adaptation strategy at different habitats with the objectives to, 1) compare biomass production and percentage of different parts at 
two slope aspects, 2) allometric growth relationship of $P$. longiflora between different biomass parts, 3) tradeoffs of biomass allocation between different organs at two slope aspects, and 4) correlation of biomass production and allocation with biotic and abiotic factors, aiming to figure out biomass production of wild plants at different habitats in the field and relevant environmental factors, for a better understanding and to explore, utilize and protect this unique medicinal plant resource.

\section{Material and methods}

\section{Study area}

The field site is located above the treeline of Mt. KaKa (32 $59^{\prime} \mathrm{N}, 103^{\circ} 40^{\prime} \mathrm{E}, 3950 \mathrm{~m}$ a.s.l), in the middle section of Minshan Mountain, eastern Tibetan Plateau (Fig. 1). Alpine meadows/steppes are the dominant ecosystems above the treeline in the Tibetan Plateau, existing in extremely harsh environments and characterized by poor soil nutrients, aridity, and low temperatures. The site experiences a mean annual precipitation of $720 \mathrm{~mm}$, with more than $70 \%$ of precipitation occurring in summers from the month of June to August. Snowfall usually occurs from the end of September to early May the following year. Vegetation presents a typical alpine meadow with numerous and unique alpine plants. Mosses are abundant and cover most of the ground. The moss layer is dominated by Polytrichum swartzii and Trematodon acutus c. mull. Vascular plants include species mainly belonging to Kobresia and Carex. Other common species in the site are Festuca, Gentiana, and Leontopodium. Plant roots in this ecosystem are generally confined to the surface A-horizon $(2-20 \mathrm{~cm})$. A few dwarf shrubs are scattered sporadically in the meadow, e.g., Rhododendron and Salix. The soil type is dominated by Mat Cry-gelic Cambisols (i.e., silty loam inceptisol) (Chinese Soil Taxonomy Research Group, 1995; Wang et al., 2014; Wang et al., 2016). Bryophytes mainly consist of Bryum pallescens, Brachythecium velutinum, Oxystegus cuspidatus, Gymnostomum anoectangioide, Bellibarbula obtusicuspis, Grimmia handelii and Drepanocladus vernicosus.

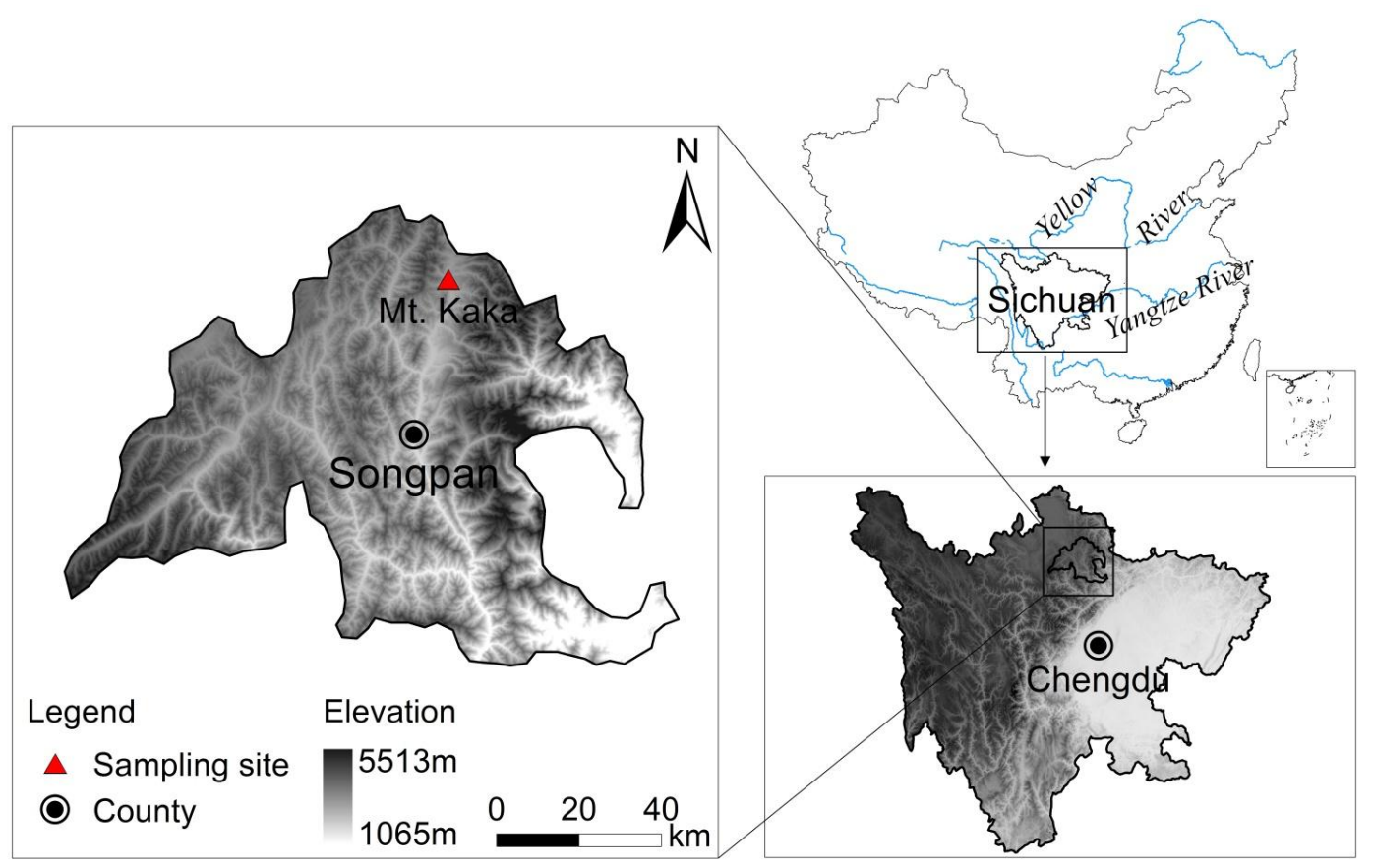

Figure 1. Location of the study sites 


\section{Experimental design}

The experiment was conducted using the nested design. We sampled object plant Pedicularis longiflora (Fig. 2a) after selecting two slope aspects in a seasonal alpine wetland, i.e. southeast, leeward with sunny, and southwest, windward with shady (Fig. $2 b)$. At each aspect, 3 plots were selected $(3 \mathrm{~m} \times 3 \mathrm{~m})$. Atmospheric temperature was measured at $20 \mathrm{~cm}$ height aboveground, and soil temperatures were measured at soil depths of $10 \mathrm{~cm}$ and $20 \mathrm{~cm}$ belowground by digital display thermometer (accuracy, $0.1^{\circ} \mathrm{C}$ ), respectively. Soil water content (SWC) was monitored by TDR (Time - domain reflectometry) soil moisture meter at $10 \mathrm{~cm}$ soil depth, with 3 replicates measured in each plot, where 3 quadrates with size of $0.5 \times 0.5 \mathrm{~m}$ were carried out for plant community survey. 30 comparable healthy individuals were selected for sampling and measuring plant height and the whole root system was carefully dug out from each slope aspect (Cornelissen et al., 2003; Pérez-Harguindeguy et al., 2013). All plant samples were brought back to the laboratory for further treatment and analysis. The plant roots were then immersed in water to remove soil from them. Following this the whole plant was sorted into four parts- root, stem, leaf, and flower and put into paper bags for oven drying for 30 minutes at $105^{\circ} \mathrm{C}$ to remove all the soil moisture and oven dried till stable weight was achieved. Dry mass of all samples was measured using an electronic balance (accuracy $0.0001 \mathrm{~g}$ ). Lastly, the biomass allocation and tradeoffs were calculated between different plant parts (Bradford and D'Amato, 2012). Flowers were considered and calculated as reproductive organs.

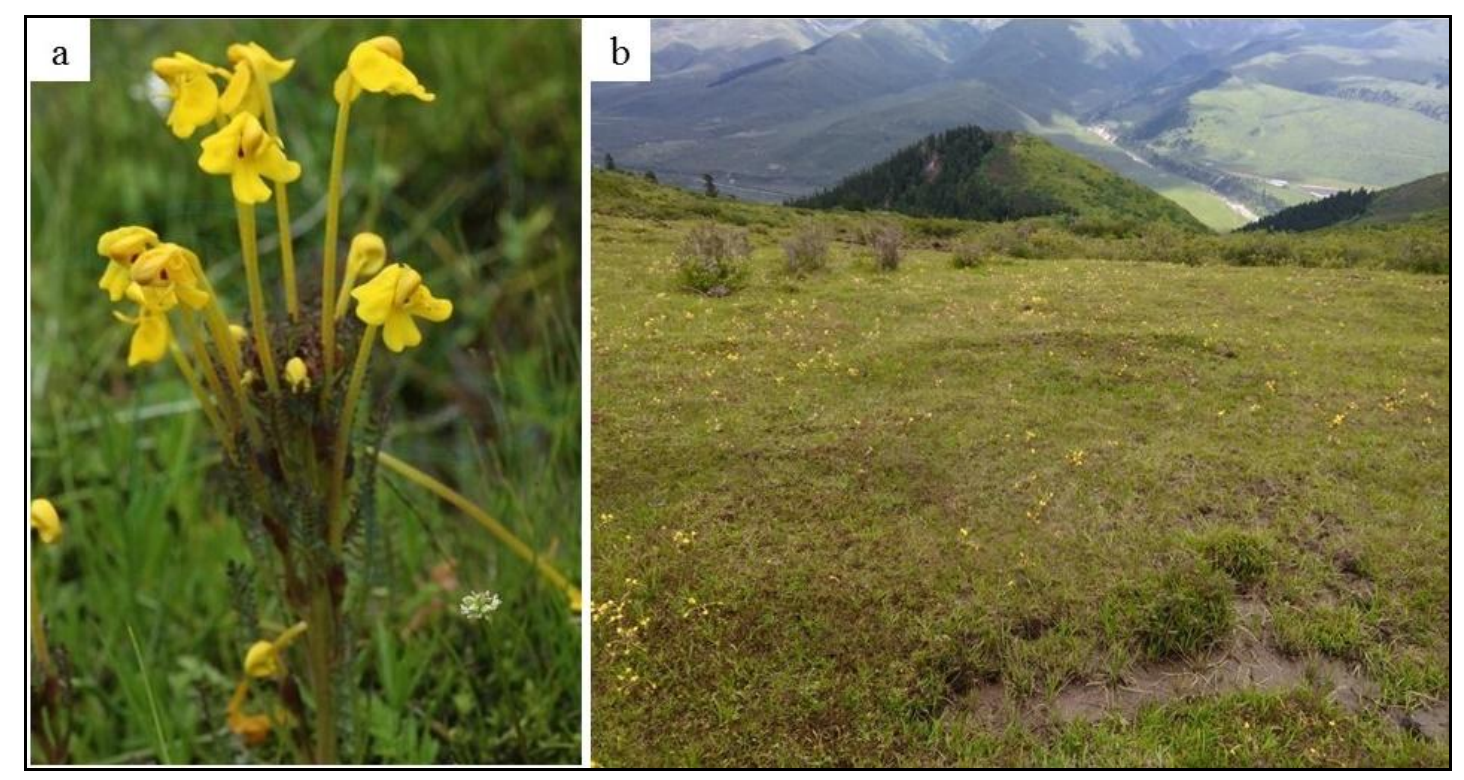

Figure 2. Photos about object plant Pedicularis longiflora (a) and its habitat (b)

\section{Data analysis}

ANOVA analysis was conducted to compare plant height and biomass of Pedicularis longiflora at different slope aspects. Allometric growth was testified among biomass of all plant parts at different aspects according to correlative growth model $\mathrm{y}=\beta \mathrm{x}^{\alpha}$. Firstly, all the biomass data was transformed with the base 10 logarithm for normal distribution. Then the equation was transformed to be $\lg =\lg \beta+\alpha \operatorname{lgx}$, $\mathrm{x}$ and $\mathrm{y}$ refer to the biomass of different parts, $\beta$ is normalized constant, $\alpha$ is allometric growth index. $\alpha=1$, indicates 
isometric growth, and $\alpha \neq 1$ indicates allometric growth (Niklas and Enquist, 2001; Niklas, 2005). Based on Warton and Weber (2002) $\alpha$ can be testified at different slope aspects by heterogeneity test. If there is no heterogeneity, a common slope can be presented in the equation (Warton and Weber, 2002). Shift A is presented by changed $\alpha$. In the case of the same $\alpha$, intercept drift test (Shift B) and coaxial drift test (Shift C) will be testified. If intercepts are different and coaxial, it is Shift B. If intercepts are identical with coaxial drift, it is Shift C. If intercept drift test (Shift B) and coaxial drift test (Shift C) occur at the same time, it is Shift D. Identical intercepts with coaxial drifts refer that X/Y has the same allometric growth relationship at different habitats (Falster et al., 2006). Index of correlation growth model can be fixed by standardized major axis (SMA) estimation (Warton et al., 2006). Intercept drift test (Shift B), coaxial drift test (Shift C) and $\alpha$ 's analysis of variance (ANOVA) are conducted by software SMATR Version 2.0. Principle Component Analysis (PCA) was applied in SAS 9.2 to figure the relationship between biomass production and environmental factors. All plots and figures have been processed with Orgin8.5. The trade-offs between different parts of the plant were calculated according to Bradford and D'Amato's (2012), which represents an effective strategy for quantifying the relationship between different paired parts of plants. Lastly, PCA was conducted to demonstrate the effects of abiotic factors and biotic factors on biomass production and allocation.

\section{Results}

\section{Plant community and environment factors at different slope aspects}

Average plant height in the community was around $3 \mathrm{~cm}$ at the southwest slope aspect, which was significantly greater than that at slope of southeast aspect $(2.54 \mathrm{~cm})$. However, the community biodiversity was significantly lower (Shannon index $=1.56$ ) at southwest aspect than that at southeast aspect (Shannon index=2.11). Moreover, there were no significant differences in community cover and evenness between the two habitats. Atmospheric temperature was $9.97 \pm 0.26{ }^{\circ} \mathrm{C}$ and $13.88 \pm 0.23{ }^{\circ} \mathrm{C}(\mathrm{F}=87.72, \mathrm{P}<0.01)$, respectively. At $10 \mathrm{~cm}$ soil depth, soil temperature was significantly higher at southwest slope aspect $\left(8.43 \pm 0.05{ }^{\circ} \mathrm{C}\right)$ than that at southeast aspect $\left(7.83 \pm 0.05{ }^{\circ} \mathrm{C}\right)$, respectively $(\mathrm{F}=7.9, \mathrm{P}<0.01)$, but there was no significant difference in soil temperature at $20 \mathrm{~cm}$ depth $(\mathrm{F}=2.52, \mathrm{P}=0.19)$ and in the soil volumetric moisture at $10 \mathrm{~cm}$ soil depth. In general, the southwest slope aspect had higher soil temperature and lower soil water content than that at southeast aspect (Table 1).

Table 1. Comparisons of general information at two different slopes

\begin{tabular}{ccc}
\hline \multirow{2}{*}{ Index } & \multicolumn{2}{c}{ Slope aspect } \\
\cline { 2 - 3 } & Southwest & Southeast \\
\hline Average plant height in community $(\mathrm{cm})$ & $3.107 \pm 0.145 \mathrm{a}$ & $2.540 \pm 0.071 \mathrm{~b}$ \\
Community cover $(\%)$ & $75 \pm 1.732 \mathrm{a}$ & $72 \pm 3.596 \mathrm{a}$ \\
Shannon index & $1.555 \pm 0.101 \mathrm{~b}$ & $2.108 \pm 0.055 \mathrm{a}$ \\
Evenness index & $0.786 \pm 0.007 \mathrm{a}$ & $0.815 \pm 0.014 \mathrm{a}$ \\
$\mathrm{T}_{\text {air }}\left({ }^{\circ} \mathrm{C}\right)$ & $9.967 \pm 0.260 \mathrm{~b}$ & $13.880 \pm 0.227 \mathrm{a}$ \\
$\mathrm{T}_{10}\left({ }^{\circ} \mathrm{C}\right)$ & $8.433 \pm 0.057 \mathrm{a}$ & $7.833 \pm 0.0504 \mathrm{~b}$ \\
$\mathrm{~T}_{20}\left({ }^{\circ} \mathrm{C}\right)$ & $8.280 \pm 0.035 \mathrm{a}$ & $8.193 \pm 0.041 \mathrm{a}$ \\
$\operatorname{VWC}_{10}(\%)$ & $65.773 \pm 0.806 \mathrm{~b}$ & $70.167 \pm 0.531 \mathrm{a}$ \\
\hline
\end{tabular}

Notes: $\mathrm{T}_{\text {air }}, \mathrm{T}_{10}$, and $\mathrm{T}_{20}$ indicate atmospheric temperature, soil temperature at $10 \mathrm{~cm}$ and $20 \mathrm{~cm}$ soil depths, respectively. $\mathrm{VWC}_{10}$ refers soil volumetric moisture at $10 \mathrm{~cm}$ below soil horizon; different letters indicate significant difference $(P<0.05)$, the same below. 


\section{Comparison of different parts of plant biomass at two different slope aspects}

P. longiflora produced less total biomass, aboveground biomass, stem biomass and flower biomass mass at southwest slope aspect than at the southeast, with $17.67 \%$, $28.42 \%, 14.7 \%, 34.14 \%, 4.42 \%$ and $24.09 \%$ lower, respectively. However, neither leaf biomass $(0.039 \mathrm{~g}$ VS $0.046 \mathrm{~g} ; \mathrm{F}=0.17, \mathrm{P}=0.68)$ and root biomass $(0.052 \mathrm{~g}$ and $0.054 \mathrm{~g}$; $\mathrm{F}=2.98, \mathrm{P}=0.086$ ) had significant differences at southwest and southeast slope aspects (Fig. 3). Besides, R/S ratio was significantly greater at southwest slope aspect $(0.66 \pm 0.06)$ than that at southeast $(0.53 \pm 0.02)$.
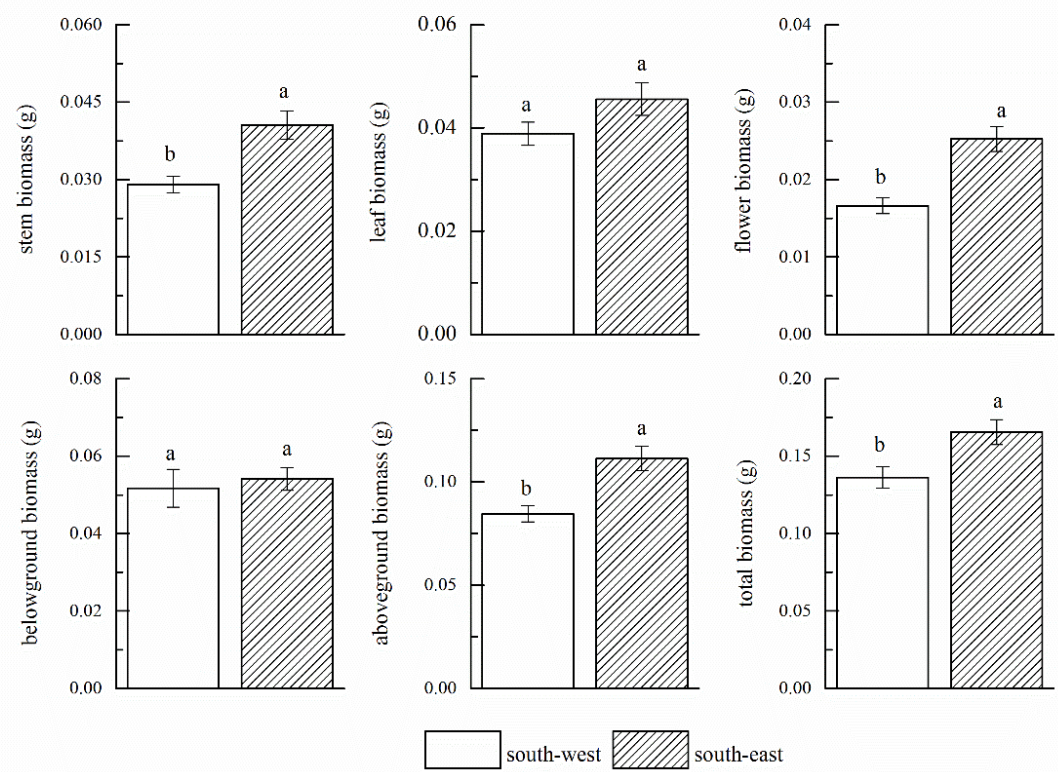

Figure 3. Biomass productions from different parts of P. longiflora at two different slope aspects (the bar is standard error, the same below).

At the blooming stage, $P$. longiflora allocated biomass to root, stem, leaf and flower as $36.81 \%, 21.81 \%, 28.22 \%$, and $13.16 \%$ of the total biomass at southwest slope aspect (Fig. 4), indicating that biomass partitioning to stem and flower have been increased with $2.00 \%$ and $3.05 \%$ of total biomass, respectively. However, the biomass allocation to root and leaf $(-3.46 \%$ and $-1.59 \%)$ decreased accordingly.

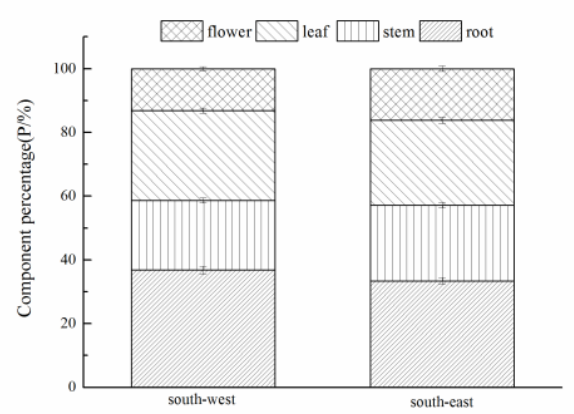

Figure 4. Biomass proportions of different organs to total biomass of P. longiflora at two slopes with different aspects. 


\section{Allometric growth relationship of $P$. longiflora between different biomass parts}

According to the paired allometric growth test, there existed significant differences of biomass at different slope aspects (Table 2, Fig. 5), except the growth relationship of biomass between root and flower. Besides, a common slope was found at both slope aspects without significant difference compared with slope $(1: 1)$, i.e., isometric growth, which indicated that environmental change did not affect allometric growth of the paired biomasses at the two habitats. There were both intercept drift and coaxial drift of fitting curves between root biomass and shoot biomass, shoot biomass and leaf biomass, leaf biomass and flower biomass, and aboveground biomass and belowground biomass at two habitats accordingly, but there was no significant difference of root-leaf biomass fitting curve between different habitats while coaxial drift existed in the fitting curve of shoot-flower biomass. When belowground biomass was fixed, plant produced greater aboveground biomass and shoot biomass at southeast slope aspect. However, there was no significant difference in leaf biomass at the two habitats with different slope aspects. With a given shoot biomass, there was greater leaf biomass at southwest slope aspect and there was also no significant difference of flower biomass with that at southeast slope aspect.

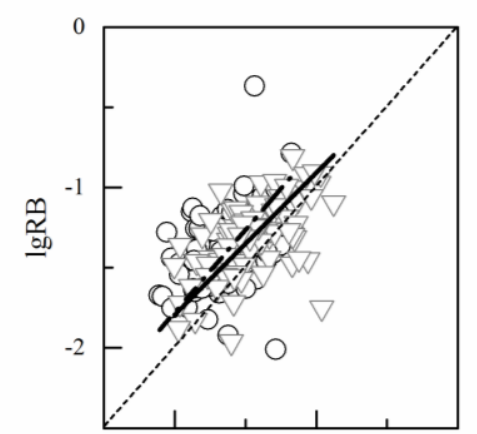

$\operatorname{lgSB}$

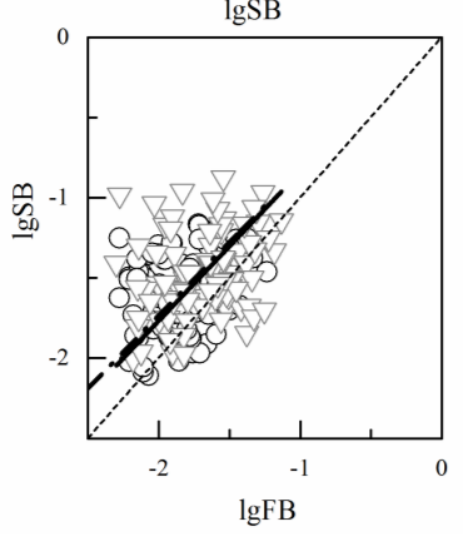

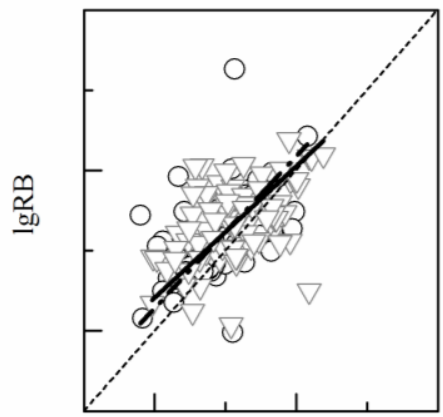

$\operatorname{lgLB}$

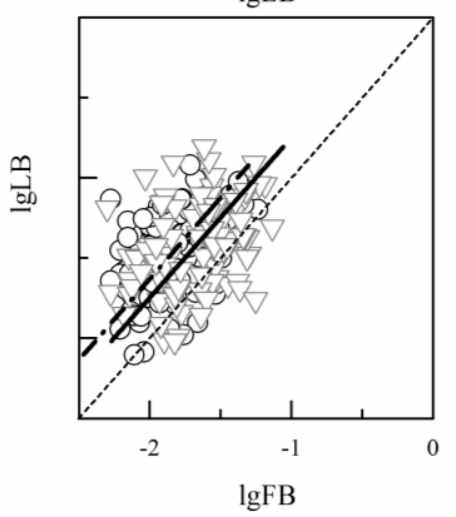

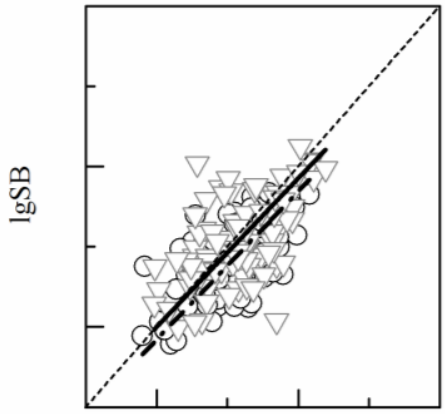

$\operatorname{lgLB}$

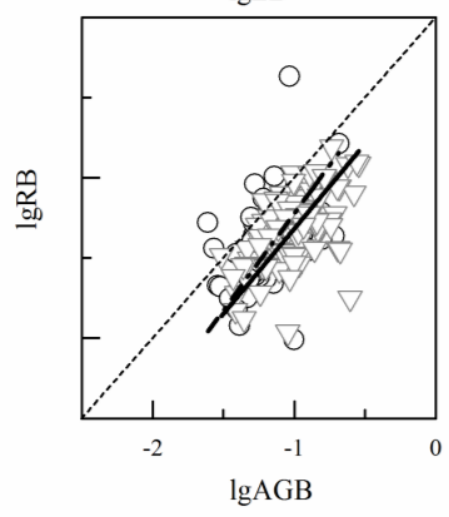

0 - $-\cdot$ south-west $\nabla \longrightarrow$ south-east

Figure 5. Linear regression (log10-log10) between fragment biomasses of $P$. longiflora at two slope exposures, RB-root biomass, $S B$-stem biomass, LB-leaf biomass, FB-flower biomass,

AGB-aboveground biomass. 
Table 2. Allometric scaling exponents ( $\alpha$ ) between paired biomass parts of P. longiflora at two slopes with different aspects

\begin{tabular}{|c|c|c|c|c|c|c|}
\hline & & \multirow[t]{2}{*}{$\mathrm{R}^{2}$} & \multirow[t]{2}{*}{$P$} & \multirow[t]{2}{*}{ A } & \multicolumn{2}{|c|}{$\begin{array}{l}\text { Test of isometric } \\
\text { growth }\end{array}$} \\
\hline & & & & & $\mathrm{F}$ & $P$ \\
\hline \multirow{6}{*}{$\begin{array}{l}\text { Root biomass vs. } \\
\text { Stem biomass }\end{array}$} & SW & 0.151 & $<0.001$ & $1.028(0.846,1.248)$ & 0.078 & 0.781 \\
\hline & SE & 0.328 & $<0.001$ & $0.710(0.590,0.856)$ & 1.948 & 0.166 \\
\hline & Common slope & $\mathrm{t}=1.277$ & 0.252 & Yes & & \\
\hline & & & & $0.946(0.831,1.076)$ & $X^{2}=0.717$ & 0.397 \\
\hline & Intercept drift & Wald $=4.934$ & 0.026 & & & \\
\hline & Coaxial drift & Wald $=6.796$ & 0.009 & & & \\
\hline \multirow{6}{*}{$\begin{array}{l}\text { Root biomass vs. } \\
\text { Leaf biomass }\end{array}$} & SW & 0.236 & $<0.001$ & $0.947(0.788,1.138)$ & 0.343 & 0.56 \\
\hline & SE & 0.202 & $<0.001$ & $0.820(0.679,0.989)$ & 4.414 & 0.038 \\
\hline & Common slope & $\mathrm{t}=1.164$ & 0.287 & Yes & & \\
\hline & & & & $0.882(0.773,1.007)$ & $X^{2}=3.459$ & 0.063 \\
\hline & Intercept drift & Wald $=0.020$ & 0.888 & & & \\
\hline & Coaxial drift & Wald $=1.874$ & 0.171 & & & \\
\hline \multirow[t]{2}{*}{$\begin{array}{l}\text { Root biomass vs. } \\
\text { Flower biomass }\end{array}$} & SW & 0.01 & 0.351 & $0.936(0.760,1.154)$ & 0.386 & 0.536 \\
\hline & SE & 0.026 & 0.132 & $0.823(0.669,1.013)$ & 3.474 & 0.066 \\
\hline \multirow{6}{*}{$\begin{array}{l}\text { Stem biomass vs. } \\
\text { Leaf biomass }\end{array}$} & SW & 0.419 & $<0.001$ & $0.921(0.785,1.082)$ & 1.019 & 0.316 \\
\hline & SE & 0.326 & $<0.001$ & $0.926(0.779,1.101)$ & 0.778 & 0.38 \\
\hline & Common slope & $\mathrm{t}=0.741$ & 0.39 & Yes & & \\
\hline & & & & $0.877(0.757,1.017)$ & $X^{2}=3.029$ & 0.082 \\
\hline & Intercept drift & Wald $=5.488$ & 0.019 & & & \\
\hline & Coaxial drift & Wald=12.267 & $<0.001$ & & & \\
\hline
\end{tabular}




\begin{tabular}{|c|c|c|c|c|c|c|}
\hline \multirow{6}{*}{$\begin{array}{l}\text { Stem biomass vs. } \\
\text { Flower biomass }\end{array}$} & SW & 0.042 & 0.052 & $0.911(0.742,1.119)$ & 0.801 & 0.373 \\
\hline & SE & 0.073 & 0.01 & $0.929(0.759,1.138)$ & 0.51 & 0.477 \\
\hline & Common slope & $\mathrm{t}=0.019$ & 0.891 & Yes & & \\
\hline & & & & $0.920(0.797,1.063)$ & $X^{2}=1.280$ & 0.258 \\
\hline & Intercept drift & Wald $=0.442$ & 0.506 & & & \\
\hline & Coaxial drift & Wald=23.034 & $<0.001$ & & & \\
\hline \multirow{6}{*}{$\begin{array}{l}\text { Flower biomass vs. } \\
\text { Leaf biomass }\end{array}$} & SW & 0.131 & $<0.001$ & $0.989(0.813,1.203)$ & 0.013 & 0.910 \\
\hline & SE & 0.113 & 0.001 & $1.004(0.823,1.224)$ & 0.002 & 0.969 \\
\hline & Common slope & $\mathrm{t}=0.012$ & 0.915 & Yes & & \\
\hline & & & & $0.996(0.867,1.145)$ & $X^{2}=0.003$ & 0.958 \\
\hline & Intercept drift & Wald $=6.588$ & 0.010 & & & \\
\hline & Coaxial drift & Wald $=10.941$ & 0.001 & & & \\
\hline \multirow{6}{*}{$\begin{array}{l}\text { Aboveground } \\
\text { biomass vs. } \\
\text { Belowground } \\
\text { biomass }\end{array}$} & SW & 0.214 & $<0.001$ & $1.203(0.998,1.450)$ & 3.860 & 0.053 \\
\hline & SE & 0.301 & $<0.001$ & $1.059(0.888,1.263)$ & 0.412 & 0.523 \\
\hline & Common slope & $\mathrm{t}=0.956$ & 0.329 & Yes & & \\
\hline & & & & $1.124(0.989,1.278)$ & $X^{2}=3.208$ & 0.073 \\
\hline & Intercept drift & Wald $=5.713$ & 0.017 & & & \\
\hline & Coaxial drift & Wald=7.049 & 0.008 & & & \\
\hline
\end{tabular}




\section{Tradeoffs of biomass allocation between different organs at two slope aspects}

Tradeoff values between reproductive biomass, vegetative biomass, leaf and non-leaf photosynthetic organs biomass were all less than 0.2 between aboveground and belowground biomass both at southwest and southeast slope aspect (Fig. O). The tradeoff value of above- and belowground biomass was quite similar between southeast (0.148) and southwest slope aspect (0.149). Tradeoff values were nearly $16 \%$ greater between reproductive organs and vegetative organs of aboveground part and $4 \%$ greater between leaf and non-photosynthetic biomass at different slope aspects. P. longiflora was prone to allocate more biomass to aboveground biomass, vegetative biomass, and non-photosynthetic organs biomass though the tradeoff values were relatively lower both at south-west slope and south-east slope aspects ( 0.149 verses 0.148 ; 0.165 verses 0.191 ; and 0.148 verses 0.154 , respectively).
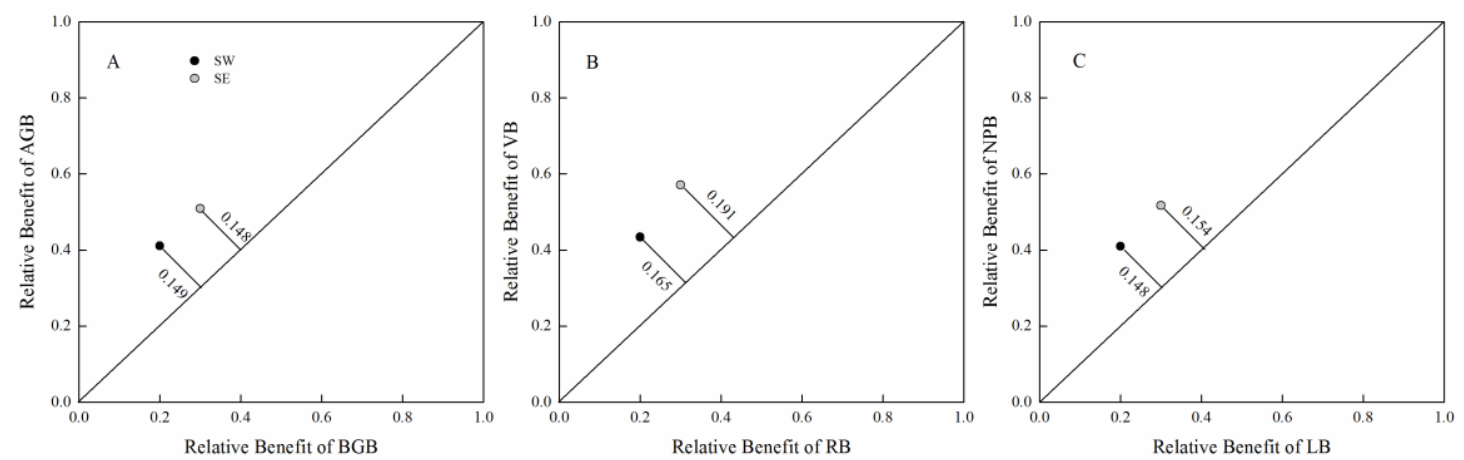

Figure 6. Trade-offs of paired biomass between two different slope aspects. The trade-off relationships are the distance between the gray dots and the 1:1 line. A: aboveground biomass $(A G B)$ vs. belowground biomass $(B G B)$, B: vegetative biomass $(V B)$ vs. reproductive biomass $(R B), C$ : non-photosynthetic organs biomass (NPB) vs. leaf biomass (LB); SW: south-west slope, SE: south-east slope

\section{Effects of environmental factors on the biomass production of P. longiflora}

The first principal component (Z1) performed as the most important factor of influence $(54.6 \%)$ consisting mostly of variations from Shannon index, air temperature, soil temperature at $10 \mathrm{~cm}$ and individual size (i.e. plant height). $\mathrm{Z2}$ contributed $19.03 \%$ to the variations from coverage, $20 \mathrm{~cm}$ soil temperatures, soil water content, and evenness (Fig. 7). The regression equations were composed of Z1 and $\mathrm{Z} 2$ as $\mathrm{TB}=0.00681 \mathrm{Z} 1-0.00856 \mathrm{Z} 2+0.15084 \quad\left(\mathrm{R}^{2}=0.403, \quad \mathrm{P}=0.012\right), \quad \mathrm{AGB}=$ $0.00671 Z 1-0.00643 Z 2+0.0979\left(\mathrm{R}^{2}=0.648, \mathrm{P}<0.001\right), \mathrm{R} / \mathrm{S}=-0.0395 \mathrm{Z} 1+0.0323 \mathrm{Z} 2+$ $0.557\left(\mathrm{R}^{2}=0.302, \mathrm{P}=0.047\right)$. Total biomass production and aboveground biomass were positively affected both by interspecies competition and temperature, and was correlated with individual size, but negatively affected by soil moisture, plant distribution and community cover. However, biomass allocation between above- and belowground (i.e. R: S ratio) had been negatively affected by component 1 (Z1) while positively affected by component 2 (Z2). 


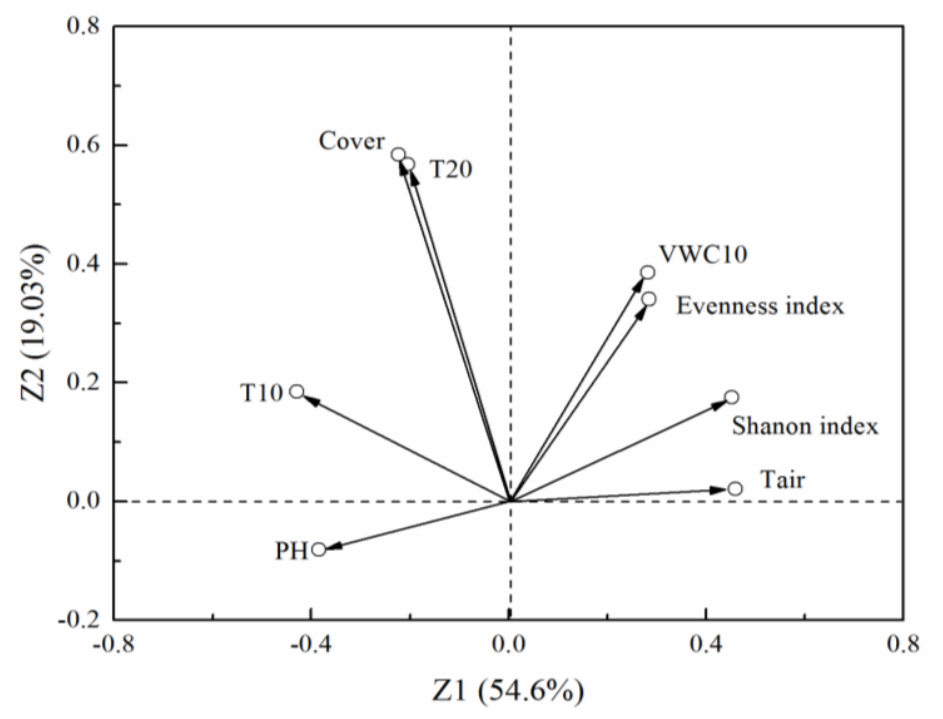

Figure 7. PCA of the effects of environment factors on biomass production and $R: S$ ratio of $P$. longiflora.

\section{Discussion}

\section{Environmental factors and biomass production at two slope aspects}

Plant leaves play an elemental role in maintaining fundamental functions of terrestrial ecosystems not only for plant photosynthesis and dry matter production but also by being an integral part of the atmosphere-plant energy exchange system (Garnier et al., 2001; Wright et al., 2001; Cornelissen et al., 2003). Moreover, plant leaves are closely related with resource absorption, utilization and use efficiency. Plant height refers to the competitive ability of light, and is also correlated with other essential elements in ecosystems (e.g., carbon sequestration) (Moles et al., 2009). Our study indicated that there was lower biodiversity, atmosphere temperature and SWC at SW slope aspect than those at SE slope aspect, but greater soil temperature and soil water content. Besides, average plant height of community at SW was significantly higher than that at SE probably due to greater soil temperature and intense evaporation as well as better precipitation because of its windward position (Table 1). Thus, plants could increase their intake of available soil nutrients and better transportation of mineral elements. It can be assumed that $P$. longiflora responded specifically to different habitats by its photosynthetic adaptive strategy and nutrient utilization.

Biomass allocation patterns have significant effects on individual growth and offspring reproduction as well as their tradeoffs with each other (Reekie and Bazzaz, 2005; Roa-Fuentes et al., 2012), which are influenced by many factors, such as plants biological characteristics, phenology patterns, and environmental heterogeneity (Fan et al., 2014). From biomass production aspect, greater total biomass and all parts of biomass were produced at SE slope aspect than those at SW slope (Fig. 3). However, the former one showed lower community coverage and average plant heights while there was greater biodiversity index and evenness. Higher air temperatures significantly accelerated metabolism to accumulate more dry matter, given that there might be more intensive competition at SE slope aspect than that at SW slope. Besides, the wind stress at SW slope may result in extra biomass investment or consumption. All integrated factors lead to greater total biomass production, although at both soil depths' temperatures were lower at 
the SE slope aspect (Table 1). From one side, more biomass had been allocated to root and leaf of plants at SW slope for better photosynthesis and nutrient transportation. From another side, plants increased portion of biomass allocation to stem and flower for supporting greater aboveground biomass and better population breeding.

\section{Allometric growth of different parts of biomass and their tradeoffs}

The results in this study indicated that there were nearly uniform regression equations' slopes of paired biomass at two slope aspects, except the relationship between root and flower, which probably was regulated by genetic effect inherent characteristics (Table 2, Fig. 5). It indicated that different plant organs probably coordinated with their growth relationships in the life history, while not associated with individual size and surrounding circumstances (Fan et al., 2014). In the isometric growth model, plants are always adjusting to adapt to environmental change for maintaining self-function and maintaining population (Li et al., 2013). However, plastic responses of biomass allocation patterns are just partially consistent with optimal partitioning theory but ontogenetically constrained (McConnaughay and Coleman, 1999), which has also been demonstrated in the results of $P$. longiflora's biomass partitioning patterns at two slope aspects, particularly the allocations of vegetative biomass and non-photosynthetic organs biomass, respectively.

There were significant differences of intercepts of the fitting curves about $P$. longiflora's root-shoot, shoot-leaf, leaf-flower, and above-belowground between SW and SE slope aspects. Given the fixed belowground biomass, plants at SE produced more stem and flower biomass that those at SW; a certain stem biomass, greater leaf biomass was produced at SW aspect; fixed leaf biomass, greater flower biomass was produced at SE aspect. Therefore, for a certain capacity of resource transportation, P. longiflora allocated more resources to flower at SE slope while at the SW slope aspect allocated more resource to leaf to ensure individual plants growth and development. An ecological trade-off between different organs was detected in relation to slope exposure, which had been observed in survivorship and fecundity in relation to seedling emergence time of Anthemis cotula in the Kashmir valley (Allaie et al., 2006). Furthermore, there were no significant differences in plant height and leaf number between the two slope aspects. Differences of survival strategy triggered by growth cycle could be excluded since plant was at the blooming stage (Körner, 2003; Reekie and Bazzaz, 2005). For medicinal values of $P$. longiflora as antivirus and antitumor, several complexes with broad biological activities have been extracted and isolated, giving rise to more attention for further study. Therefore, the studies of survival strategy mechanism also need to integrate ecological characteristics (i.e. photosynthetic physiology), secondary metabolite and nutrient content dynamics in future (Westoby et al., 2002).

Tradeoffs of above- and belowground biomass varied at different slope aspects somehow, but just a little about other two pairs (Fig. 6). Plants homeostasis played a more important part with slight appropriate readjustments to adapt to environmental change. Both abiotic and biotic factors affected biomass production and partitioning between above- and belowground biomass (Fig. 7), which was also correlated with plant size (referred as plant height). Nevertheless, R: S ratio was negatively correlated with the first component (Shannon index, air temperature, $10 \mathrm{~cm}$ soil temperatures and individual size), which might have been triggered by the belowground biomass interaction with environmental factors, though not very significant.

In summary, this study integrate traditional knowledge with ecosystem functioning and services approach by studying the medicinal properties of wild plants and their circumstances as well as the interactions between plant production and environmental factors, in particular, for heterogeneous sites in alpine meadow even if at a small scale or short distance (Körner, 2003). There existed significant differences of biodiversity, 
atmospheric temperature, soil temperature, and soil water content between habitats at different slope aspects. $P$. longiflora had greater individual size at SW slope aspect for better photosynthesis and adaptation strategy. Besides, plants allocated more biomass to reproduction organ at SE slope aspect. From a standpoint of resource conservation of medicinal herbs, SE slopes can be a preferred habitat for the growth and reproduction of $P$. longiflora. It has been characterized and represented by biomass allocation and its correlation with environmental factors about adaptation and response strategy to environmental change, which not only builds the model for assessing ecosystems, but also estimating its function and service. The biomass production of $P$. longiflora had been co-influenced by both biotic and abiotic factors with species diversity and soil temperature as key indicators to culture plants for medicinal utilization, which can be used to guide practical implications of using traditional knowledge for different products and for the sustainable utilization of wild plant resources of the alpine meadow.

Acknowledgments. This work was supported by China Postdoctoral Science Foundation under Grant (2014M552385), and National Natural Science Foundation of China under Grant (31400389).

\section{REFERENCES}

[1] Allaie, R. R., Reshi, Z., Wafai, B. A. (2006): Demographic plasticity in relation to growth and resource allocation pattern in Anthemis cotula - an alien invasive species in Kashmir Himalaya, India. - Applied Ecology and Environmental Research 4(1): 63-74.

[2] Bradford, J. B., D'amato, A. W. (2012): Recognizing trade-offs in multi-objective land management. - Frontiers in Ecology and the Environment 10(4): 210-216.

[3] Chinese Soil Taxonomy Research Group. (1995): ISSAS. Chinese Soil Taxonomy. Science Press, Beijing.

[4] Chu, H. B., Tan, N. H., Peng, S. C (2009): Progress in research on Pedicularis plants. China Journal of Chinese Materia Medica 34(19): 2536-2546. (in Chinese with English abstract)

[5] Cornelissen, J. H. C., Lavorel, S., Garnier, E., Díaz, S., Buchmann, N., Gurvich, D. E., Reich, P. B., ter Steege, H., Morgan, H.D., van der Heijden, M. G. A. Pausas, J. G., Poorter, H. (2003): A handbook of protocols for standardised and easy measurement of plant functional traits worldwide. - Australian Journal of Botany 51(4): 335-380.

[6] Enquist, B. J., Brown, J. H., West, G. B (1998): Allometric scaling of plant energetics and population density. - Nature 395(6698): 163-165.

[7] Enquist, B. J., Niklas, K. J. (2002): Global allocation rules for patterns of biomass partitioning in seed plants. - Science 295(5559): 1517-1520.

[8] Fan, X, Lin, Z, Ding, X, Zhu, J, University, L. (2014): Sexual size dimorphism and female individual fecundity of Silurus asotus and Clarias fuscus. - Acta Ecologica Sinica 34(3): 555-563.

[9] Falster, D. S., Warton, D. I., Wright, I. J. (2006): User's guide to smatr: Standardised major axis tests and routines, http://www.bio.mq.edu.au/ecology/SMATR. , Version 2.0 edn.

[10] Garnier, E., Laurent, G., Bellmann, A., Debain, S., Berthelier, P., Ducout, B., Roumet, C., Navas, M. L. (2001): Consistency of species ranking based on functional leaf traits. - New Phytologist 152(1): 69-83.

[11] Körner, C. (2003): Alpine plant life: functional plant ecology of high mountain ecosystems. - Springer Science and Business Media.

[12] Li, Y., Zhao, C. Z., Hou, Z. J., Ma, X. L., Zhang, Q. (2013): Body size and stem-and leaf allometry of Stellera chamaejasme in degraded alpine grassland. - Chinese Journal of Ecology 32(2): 241-246. (in Chinese with English abstract) 
[13] McConnaughay, K. D. M., Coleman, J. S. (1999): Biomass allocation in plants: ontogeny or optimality? A test along three resource gradients. - Oecologia 113: 447-455.

[14] Moles, A. T., Warton, D. I., Warman, L., Swenson, N. G., Laffan, S. W., Zanne, A. E., Pitman, A., Hemmings, F. A., Leishman, M. R. (2009): Global patterns in plant height. Journal of Ecology 97(5): 923-932.

[15] Niklas, K. J., Enquist, B. J. (2001): Invariant scaling relationships for interspecific plant biomass production rates and body size. - Proceedings of the National Academy of Sciences of the United States of America 98(5): 2922-2927.

[16] Niklas, K. J. (2005): Modelling below- and above-ground biomass for non-woody and woody plants. - Annals of Botany 95(2): 315-321.

[17] Patty, L., Halloy, S. R. P., Hiltbrunner, E, Korner, C. (2010): Biomass allocation in herbaceous plants under grazing impact in the high semi-arid andes. - Flora 205(10): 695-703.

[18] Pérez-Harguindeguy, N., Díaz, S., Garnier, E., Lavorel, S., Poorter, H., Jaureguiberry, P., Bret-Harte, M. S., Cornwell, W. K., Craine, J. M., Gurvich, D. E., Urcelay, C., Veneklaas, E. J., Reich, P. B., Poorter, L., Wright, I. J., Ray, P., Enrico, L., Pausas, J. G., De Vos, A. C., Buchmann, N., Funes, G., Quétier, F,. Hodgson, J. G., Thompson, K., Morgan, H. D., Ter Steege, H., Sack, L., Blonder, B., Poschlod, P., Vaieretti, M. V., Conti, G., Staver, A. C, Aquino, S., Cornelissen, J. H. C. (2013): New handbook for standardised measurement of plant functional traits worldwide. - Australian Journal of Botany 61(3): 167-234.

[19] Poorter, L., Bongers, F., Sterck, F. J., Woll, H. (2003): Architecture of 53 rain forest tree species differing in adult stature and shade tolerance. - Ecology 84: 602-608.

[20] Poorter, H., Niklas, K. J., Reich, P. B., Oleksyn, J., Poot, P., Mommer, L. (2012): Biomass allocation to leaves, stems and roots: Meta-analyses of interspecific variation and environmental control. - New Phytologist 193(1): 30-50.

[21] Reekie, E. G., Bazzaz, F. A. (2005): Reproductive allocation in plants. - Academic Press; Burlington.

[22] Roa-Fuentes, L. L., Campo, J., Parra-Tabla, V. (2012): Plant biomass allocation across a precipitation gradient: An approach to seasonally dry tropical forest at Yucatan, Mexico. - Ecosystems 15(8): 1234-1244.

[23] Shipley, B., Meziane, D. (2002): The balanced growth hypothesis and the allometry of leaf and root biomass allocation. - Functional Ecology 16(3): 326-331.

[24] Song, M. H., Tian, Y. Q., Xu, X. L., Hu, Q. W., Hua, O. Y. (2006): Interactions between root and shoot competition among four plant species in an alpine meadow on the tibetan plateau. - Acta Oecologica-International Journal of Ecology 29(2): 214-220.

[25] Stearns, S. C. (1992): The Evolution of Life Histories. - Oxford University Press, Oxford.

[26] Sun, S., Frelich, L. E. (2011): Flowering phenology and height growth pattern are associated with maximum plant height, relative growth rate and stem tissue mass density in herbaceous grassland species. - Journal of Ecology 99(4): 991-1000.

[27] Wang, C. Z., Jia, Z. J. (1996): Purine Nucleosides from Pedicularis longiflora. - Journal of Lanzhou University (natural science) 32(4): 91-95. (in Chinese with English abstract)

[28] Wang, J. N., Shi, F. S., Xu, B., Wang, Q., Wu, Y., Wu, N. (2014): Uptake and recovery of soil nitrogen by bryophytes and vascular plants in an alpine meadow. - Journal of Mountain Science 11(2): 475-484.

[29] Wang, J. N., Xu, B., Wu, Y., Gao, J., Shi, F. S. (2016): Flower litters of alpine plants affect soil nitrogen and phosphorus rapidly in the eastern Tibetan Plateau. - Biogeosciences 13: 1-13. doi:10.5194/bg-2016-68.

[30] Warton, D. I., Weber, N. C. (2002): Common slope tests for bivariate errors-in-variables models. - Biometrical Journal 44(2): 161-174. 
[31] Warton, D. I., Wright, I. J., Falster, D. S., Westoby, M. (2006): Bivariate line-fitting methods for allometry. - Biological Reviews of the Cambridge Philosophical Society 81 (2): 259-291.

[32] Weiner, J. (2004): Allocation, plasticity and allometry in plants. - Perspectives in Plant Ecology Evolution and Systematics 6(4): 207-215.

[33] Westoby, M. (1998): A leaf-height-seed (LHS) plant ecology strategy scheme. - Plant and Soil 199: 213-227.

[34] Westoby, M., Falster, D. S., Moles, A. T., Vesk, P. A., Wright, I. J. (2002): Plant ecological strategies: some leading dimensions of variation between species. - Annual Review of Ecology and Systematics 33: 125-159.

[35] Wright, I. J., Reich, P. B., Westoby, M. (2001): Strategy shifts in leaf physiology, structure and nutrient content between species of high and low rainfall and high and low-nutrient habitats. - Functional Ecology 15(4): 423-434.

[36] Wu, J. B., Hong, J. T., Wang, X. D., Sun, J., Lu, X. Y. Fan, J. H., Cai, Y. J. (2013): Biomass partitioning and its relationship with the environmental factors at the alpine steppe in northern Tibet. - PLoS ONE 8 (12): e81986.

[37] Zhao, X. Q. (2009): Alpine meadow ecosystem and global change.- Science Press, Beijing. 